\title{
Paravertebral blocks and enhanced recovery after surgery protocols in breast reconstructive surgery: patient selection and perspectives
}

This article was published in the following Dove Press journal: Journal of Pain Research

\author{
Rajiv P Parikh \\ Terence M Myckatyn \\ Department of Surgery, Division of \\ Plastic and Reconstructive Surgery, \\ Washington University School of \\ Medicine, St Louis, MO, USA
}

\begin{abstract}
The management of postoperative pain is of critical importance for women undergoing breast reconstruction after surgical treatment for breast cancer. Mitigating postoperative pain can improve health-related quality of life, reduce health care resource utilization and costs, and minimize perioperative opiate use. Multimodal analgesia pain management strategies with nonopioid analgesics have improved the value of surgical care in patients undergoing various operations but have only recently been reported in reconstructive breast surgery. Regional anesthesia techniques, with paravertebral blocks (PVBs) and transversus abdominis plane (TAP) blocks, and enhanced recovery after surgery (ERAS) pathways have been increasingly utilized in opioid-sparing multimodal analgesia protocols for women undergoing breast reconstruction. The objectives of this review are to 1) comprehensively review regional anesthesia techniques in breast reconstruction, 2) outline important components of ERAS protocols in breast reconstruction, and 3) provide evidence-based recommendations regarding each intervention included in these protocols. The authors searched across six databases to identify relevant articles. For each perioperative intervention included in the ERAS protocols, the literature was exhaustively reviewed and evidence-based recommendations were generated using the Grading of Recommendations, Assessment, Development, and Evaluation system methodology. This study provides a comprehensive evidence-based review of interventions to optimize perioperative care and postoperative pain control in breast reconstruction. Incorporating evidence-based interventions into future ERAS protocols is essential to ensure high value care in breast reconstruction. Keywords: enhanced recovery after surgery, ERAS, postmastectomy breast reconstruction, autologous flap, breast implant
\end{abstract}

\section{Introduction}

Breast reconstruction after surgical treatment for breast cancer has the potential to significantly improve patients' health-related quality of life. ${ }^{1-7}$ Although most women report greater satisfaction with appearance and improved physical, psychosocial, and sexual well-being following breast reconstruction, the management of postoperative pain remains challenging. Inadequate postoperative pain control contributes to unnecessary health care resource utilization while exacerbating costs and hindering patient recovery. This is true for both implant-based (prosthetic) and microvascular (autologous) breast reconstruction techniques. Nearly one-half of patients undergoing breast reconstruction experience postoperative pain syndromes. ${ }^{8}{ }^{89}$ Inadequately controlled acute postoperative pain is associated with an increased likelihood of developing persistent postsurgical pain, which reduces the quality of life.$^{8-12}$ Additionally, poorly controlled pain may result in a prolonged opioid dependency, contributing to the ongoing opioid epidemic in the
Correspondence: Terence M Myckatyn Department of Surgery, Division of Plastic and Reconstructive Surgery, Washington University School of

Medicine, 1020 North Mason Road, Suite I I0, Building 3, St Louis, MO 63।4I, USA

Tel + I 3 I4 9963255

Email myckatyn@wustl.edu 
United States. ${ }^{13,14}$ Furthermore, postoperative pain negatively impacts the quality of recovery (QoR) and satisfaction. ${ }^{15-17}$ There is evidence that a decrease in QoR secondary to pain can prolong hospital stay, delay return to normal daily living, and reduce the quality of life..$^{15-19}$ Thus, opioid-sparing analgesic strategies to improve postoperative pain control, reduce length of stay (LOS), and minimize resource utilization are essential to improve the overall quality and value of care for patients undergoing breast reconstruction. ${ }^{20-22}$

Recently, there have been a few interventions introduced that have promise in optimizing pain control and postoperative recovery for women with breast cancer undergoing breast reconstruction. The most prevalent of these are regional anesthesia techniques, including paravertebral blocks (PVBs) and transversus abdominis plane (TAP) blocks, and evidencebased multimodal perioperative management approaches, referred to as Enhanced Recovery after Surgery (ERAS) protocols. The purported strengths of these interventions are that they significantly improve the value of surgical care by enhancing postoperative recovery. ${ }^{23-27}$ ERAS protocols utilize evidence-based recommendations to standardize perioperative care. ${ }^{28}$ Although widely adopted in various surgical disciplines, there was minimal literature on opioid-sparing multimodal analgesia strategies in reconstructive breast surgery until recently. ${ }^{29}$ As a result, perioperative approaches have traditionally been based on individual experience and differed tremendously across institutions, potentially contributing to variations in system-wide quality and unnecessary resource utilization. Therefore, the goals of this article are to 1) comprehensively review regional anesthesia techniques in breast reconstruction, 2) outline important components of ERAS protocols in breast reconstruction, and 3) provide evidencebased recommendations regarding all perioperative interventions aimed at enhancing recovery in breast reconstruction.

\section{Methods}

This study was conducted in the following two stages: 1) comprehensive review of regional analgesic techniques and ERAS protocols in breast reconstruction and 2) literature review and generation of evidence-based recommendations for all interventions included in ERAS protocols for breast reconstruction. The authors followed the Preferred Reporting Items for Systematic Reviews and Meta-Analyses (PRISMA) guidelines throughout this investigation. ${ }^{30,31}$

\section{Review of regional analgesia techniques and ERAS protocols in breast reconstruction}

To identify regional analgesia and ERAS protocols, we searched the Ovid MEDLINE, EMBASE, SCOPUS, Web of Science, Cochrane Central Register of Controlled Trials, and ClinicalTrials.gov databases from January 1990 through October 2017 using strategies designed by a medical librarian for the concepts of breast reconstruction, regional analgesia, perioperative care or fast track or enhanced recovery, and LOS, postoperative complications, or pain. All results were exported to EndNote, and duplicate citations were removed. References were then hand-searched, and relevant articles were retrieved. All studies reporting patients undergoing breast reconstruction in an ERAS protocol or with regional analgesia techniques were eligible for inclusion. Articles in all languages were considered. A study was excluded if full text could not be obtained.

\section{Evidence-based recommendations for ERAS protocol items}

In the second stage, we performed a literature review of each intervention included in the previously identified ERAS protocols with search parameters for $[\mathrm{X}]$ and breast reconstruction, where $\mathrm{X}=$ specific intervention in the ERAS protocol. For each item, searches were performed to identify the best available evidence, with priority given to metaanalyses, systematic reviews, and randomized-controlled trials (RCTs). In the absence of high-quality evidence specific to breast reconstruction, we included nonrandomized observational studies and/or extrapolated evidence from the surgical literature. Consistent with other studies, we used the Grading of Recommendations, Assessment, Development, and Evaluation (GRADE) system to appraise the overall quality of evidence for each intervention and to assign a level of strength to each recommendation. ${ }^{32-36}$ The GRADE system is widely adopted, and the preferred methodology of The Cochrane Collaboration and the Agency for Healthcare Research and Quality (AHRQ) for grading clinical evidence and developing recommendations for clinical practice is used. ${ }^{37}$ The GRADE approach classifies recommendations into two levels, such as strong (Grade 1) and weak (Grade 2), and then subclassifies each grade into three categories based on the quality of evidence $(\mathrm{A}=$ high quality, $\mathrm{B}=$ moderate quality, and $\mathrm{C}=$ low quality). ${ }^{38-40}$ The strength of recommendation is primarily influenced by the tradeoff between the benefits, risks, and burdens of an intervention and by the quality of the evidence available.

\section{Regional analgesic techniques in breast reconstruction}

Regional anesthesia techniques are utilized across surgical disciplines and have demonstrated efficacy at reducing both 
acute and chronic postoperative pain, opiate use, and LOS for various surgical procedures. ${ }^{41}$ In reconstructive breast surgery, the two most common techniques for regional anesthesia are PVBs and TAP blocks. PVBs are utilized in both prosthetic and autologous breast reconstruction procedures, whereas TAP blocks only have utility in abdominally based autologous breast reconstruction procedures such as deep inferior epigastric artery perforator (DIEP) flaps and transverse rectus abdominis myocutaneous (TRAM) flaps. Traditionally, regional blocks or infusions were performed with bupivacaine, which has a duration of action between 8 and 12 hours. However, recently, several groups have shifted toward using liposomal bupivacaine, which has a duration of action ranging from 72 to 96 hours. ${ }^{42}$ Although comparative studies evaluating cost and outcomes between bupivacaine and liposomal bupivacaine are still needed, there is preliminary evidence to demonstrate the efficacy and merit the use of liposomal bupivacaine in reconstructive breast surgery. ${ }^{43}$

\section{TAP blocks}

TAP blocks were initially introduced in the literature in the early 2000s and have subsequently gained widespread acceptance as an effective technique for regional anesthesia in various abdominally based surgical operations. ${ }^{44,45}$ In abdominally based autologous breast reconstruction procedures, TAP blocks were first reported as having efficacy for improving pain control and reducing opiate requirements by Hivelin et $\mathrm{al}^{46}$ in 2011. To date, there is evidence from one $\mathrm{RCT}$, two prospective cohort studies, and two retrospective studies demonstrating that TAP blocks are safe and significantly reduce postoperative opioid use in abdominally based autologous breast reconstruction. ${ }^{4-50}$ There are several excellent articles that detail the relevant anatomy and technical components of performing a TAP block. ${ }^{51,52}$ Briefly, TAP blocks involve anesthetizing the sensory innervation to the anterior abdominal wall, which is traditionally considered to be derived from the T6-L1 nerves from the anterior rami of the thoracolumbar spinal nerves. ${ }^{51,52}$ The lumbar triangle of Petit is often used as the primary landmark to localize the injection to the plane between the internal oblique musculature and the transversus abdominis musculature. In autologous breast reconstruction, this block is performed under direct visualization following flap harvest and prior to closure of the abdominal donor site. A blunt tip injection cannula is inserted into the TAP and local anesthetic in the form of bupivacaine or liposomal bupivacaine is injected. Alternatively, a catheter can also be introduced in the plane and redosed periodically in the perioperative period. ${ }^{47,48}$ For bilateral procedures, bilateral blocks are performed.

\section{PVBs}

There is considerable evidence supporting the use of PVBs in breast surgery. In a meta-analysis of 15 RCTs in breast cancer surgery, PVBs were determined to be effective at reducing postoperative pain and hospital LOS. ${ }^{53}$ In reconstructive breast surgery, there is literature to support the use of PVBs in both prosthetic breast reconstruction and autologous breast reconstruction procedures. A recent prospective study by Parikh et $a 1^{54}$ demonstrated a significant reduction in postoperative pain and LOS for women with breast cancer undergoing postmastectomy abdominally based autologous breast reconstruction with a PVB compared to women who did not receive a PVB. In a follow-up study from the same group, the authors also reported a reduction in opiate medication requirements for patients undergoing autologous breast reconstruction with use of a PVB compared to patients undergoing autologous breast reconstruction without a PVB. ${ }^{55}$ Of importance, the use of PVBs did not compromise intraoperative perfusion or change fluid requirements in this cohort. The value of PVBs is not confined to abdominally based breast reconstruction. In 2016, Unkart et al ${ }^{56}$ reported their experience with PVBs for patients undergoing breast reconstruction with latissimus dorsi autologous flaps. In prosthetic breast reconstruction, there are several retrospective cohort studies and one RCT that similarly confirm the value of PVBs versus general anesthesia alone. Coopey et $\mathrm{al}^{57}$ and Fahy et $\mathrm{al}^{58}$ independently demonstrated reductions in LOS, perioperative opiate use, and postoperative pain for patients undergoing immediate prosthetic breast reconstruction with a PVB compared to patients who did not receive a PVB. This reduction in perioperative opiate use was subsequently confirmed in a 2015 report by Glissmeyer et al, ${ }^{59}$ where the authors reported that morphine equivalents were significantly lower in the cohort of patients who received a PVB in postmastectomy breast reconstruction compared to the cohort of patients who did not. In 2016, Wolf et al reported results from the first prospective RCT of PVBs in prosthetic breast reconstruction. In a total of 74 patients (35 who received a PVB and 34 in the control group), the authors demonstrated that patients who received a PVB, compared to patients who did not, required significantly less opiates intraoperatively and postoperatively, had lower pain scores postoperatively, and required less antiemetic medications perioperatively. ${ }^{60}$ These procedures can be performed with consistency and 
with minimal risk for complications, as confirmed in a 2016 report of 856 patients undergoing 1427 PVBs for regional anesthesia in postmastectomy prosthetic reconstructive breast surgery procedures where the complication rate was $<1.0 \%{ }^{61}$ Similar to TAP blocks, there are excellent articles that detail the anatomical and technical considerations for performing PVBs. ${ }^{61,62}$ Briefly, our preferred approach is to inject $15-20 \mathrm{~mL}$ of $0.5 \%$ bupivacaine (bilateral for bilateral procedures) at the $\mathrm{T} 2-\mathrm{T} 4$ paravertebral spaces under ultrasound guidance in the immediate preoperative setting. ${ }^{54,55}$ These procedures are performed by fellowship trained anesthesiologists on a dedicated regional block team.
Recommendation: There is moderate-quality evidence to support the inclusion of regional analgesic techniques with TAP blocks and PVBs in ERAS protocols for microvascular breast reconstruction and PVBs for prosthetic breast reconstruction (Grade 1B).

\section{ERAS protocols in breast reconstruction}

Following review, there were five nonrandomized studies from four different institutions that evaluated ERAS protocols in breast reconstruction (Table 1). ${ }^{63-67}$ In total, studies evaluated 49 patients undergoing prosthetic reconstruction and 661

Table I Characteristics of studies comparing breast reconstruction outcomes for patients in an ERAS protocol to conventional care

\begin{tabular}{|c|c|c|c|c|c|c|c|}
\hline Authors & Location & Year & Methods & $\begin{array}{l}\text { Participants } \\
\text { in ERAS } \\
\text { protocol, } \mathbf{n}\end{array}$ & $\begin{array}{l}\text { Participants } \\
\text { in usual care } \\
\text { protocol, } \mathbf{n}\end{array}$ & $\begin{array}{l}\text { Perioperative interventions } \\
\text { included in ERAS protocol }\end{array}$ & Outcomes \\
\hline $\begin{array}{l}\text { Batdorf } \\
\text { et al }{ }^{64}\end{array}$ & USA & 2015 & $\begin{array}{l}\text { Retrospective } \\
\text { cohort }\end{array}$ & 49 & 51 & $\begin{array}{l}\text { Preoperative education; fasting only } \\
2 \text { hours for clear liquids prior to } \\
\text { surgery; antimicrobial prophylaxis; } \\
\text { multimodal analgesia with opiates, } \\
\text { NSAIDs, acetaminophen, gabapentin } \\
\text { + TAP blocks with liposomal } \\
\text { bupivacaine; euvolemia fluid } \\
\text { management; antiemetics; oral feeding } \\
\text { on POD 0; early ambulation; urinary } \\
\text { catheter removal POD I }\end{array}$ & $\begin{array}{l}\text { Length of stay, } \\
\text { total opiate use, } \\
\text { pain scores, flap } \\
\text { loss, systemic } \\
\text { complications, surgical } \\
\text { complications }\end{array}$ \\
\hline $\begin{array}{l}\text { Bonde } \\
\text { et a }{ }^{65}\end{array}$ & Denmark & 2015 & Case-control & 177 & 277 & $\begin{array}{l}\text { Preoperative education; antimicrobial } \\
\text { prophylaxis; multimodal analgesia } \\
\text { with opiates (on request), NSAIDs } \\
\text { and acetaminophen; early ambulation; } \\
\text { urinary catheter removal POD I }\end{array}$ & $\begin{array}{l}\text { Length of stay, } \\
\text { surgical complications, } \\
\text { flap loss }\end{array}$ \\
\hline $\begin{array}{l}\text { Bonde } \\
\text { et } \mathrm{al}^{66}\end{array}$ & Denmark & 2016 & $\begin{array}{l}\text { Retrospective } \\
\text { cohort }\end{array}$ & 16 & $\mathrm{~N} / \mathrm{A}$ & $\begin{array}{l}\text { Preoperative education; antimicrobial } \\
\text { prophylaxis; multimodal analgesia } \\
\text { with opiates (on request), NSAIDs, } \\
\text { acetaminophen, and gabapentin; } \\
\text { minimally invasive approach (DIEP } \\
\text { flaps only); oral feeding on POD I; } \\
\text { early ambulation; urinary catheter } \\
\text { removal POD I }\end{array}$ & $\begin{array}{l}\text { Length of stay, } \\
\text { surgical complications, } \\
\text { flap loss }\end{array}$ \\
\hline $\begin{array}{l}\text { Afonso } \\
\text { et al }{ }^{63}\end{array}$ & USA & 2017 & $\begin{array}{l}\text { Retrospective } \\
\text { cohort }\end{array}$ & 42 & 49 & $\begin{array}{l}\text { Preoperative education; fasting only } \\
2 \text { hours for clear liquids prior to } \\
\text { surgery; multimodal analgesia with } \\
\text { opiates, NSAIDs (IV ketorolac), and } \\
\text { acetaminophen + TAP blocks with } \\
\text { liposomal bupivacaine; goal-directed } \\
\text { fluid management; antiemetics; oral } \\
\text { feeding on POD I; early ambulation; } \\
\text { urinary catheter removal POD I }\end{array}$ & $\begin{array}{l}\text { Length of stay, } \\
\text { total opiate use, } \\
\text { pain scores, flap } \\
\text { loss, systemic } \\
\text { complications, surgical } \\
\text { complications }\end{array}$ \\
\hline $\begin{array}{l}\text { Dumestre } \\
\text { et a }\left.\right|^{67}\end{array}$ & Canada & 2017 & $\begin{array}{l}\text { Retrospective } \\
\text { cohort }\end{array}$ & 29 & 29 & $\begin{array}{l}\text { Preoperative education; fasting only } \\
3 \text { hours for clear liquids prior to } \\
\text { surgery; multimodal analgesia with } \\
\text { opiates, celecoxib/NSAIDs, and } \\
\text { acetaminophen + local nerve blocks } \\
\text { with bupivacaine }\end{array}$ & $\begin{array}{l}\text { Length of stay, } \\
\text { QoR scores, pain } \\
\text { scores, systemic } \\
\text { complications, surgical } \\
\text { complications }\end{array}$ \\
\hline
\end{tabular}

Abbreviations: DIEP, deep inferior epigastric artery perforator; ERAS, enhanced recovery after surgery; NSAIDs, nonsteroidal anti-inflammatory drugs; POD, postoperative day; QoR, quality of recovery; TAP, transversus abdominis plane; N/A, not available. 
patients undergoing 783 microvascular flaps for autologous reconstruction. Of them, 29 patients undergoing prosthetic reconstruction and 284 patients undergoing 345 flaps were treated in an ERAS protocol, whereas 29 patients undergoing prosthetic reconstruction and 377 patients undergoing 438 flaps were treated with conventional care. There were two studies from the same group: the first study, published in 2015, compared an ERAS protocol with conventional care and the second study, published in 2016, reported on 16 patients in a modified ERAS protocol, which was then compared with their previously published data on patients in the first version of the ERAS protocol. ${ }^{65,66}$ There was substantial heterogeneity between the treatment protocols, patient groups, comorbidities reported, and postoperative outcomes measured; therefore, quantitative analyses across studies were not feasible. In regard to outcomes reported, all studies reported LOS, but only three studies reported postoperative pain scores, two studies reported opiate use, and three studies reported systemic complications. No study reported cost outcomes. Additionally, data on relevant covariates or potential confounders were inconsistently reported.

\section{Evidence-based recommendations for components of ERAS protocols Preoperative interventions}

Patient education/counseling

Preoperative patient education and counseling are essential to patient-centered care, one of the key domains of high-quality health care ${ }^{68}$ Patient education and counseling should address patients' expectations, include a comprehensive discussion of the risks and benefits of different treatment options, assess patients' understanding of their expected perioperative course, and involve patients in the decision-making process. ${ }^{69,70}$ In breast reconstruction, several studies, utilizing the BREAST-Q patient-reported outcome measure, have shown a positive association between patient's satisfaction with preoperative information and postoperative outcome. ${ }^{71,72}$ Additionally, Sheehan et $\mathrm{al}^{73}$ and Zhong et $\mathrm{al}^{74}$ independently demonstrated that lower satisfaction with preparatory information is associated with an increased likelihood of regret following breast reconstruction. When expanded across surgical specialties, there is also evidence that preoperative education is an independent predictor of reduced LOS in ERAS protocols. ${ }^{75-77}$

Recommendation: Preoperative education is integral to patient-centered care and has the potential to improve postoperative patient-reported outcomes while minimizing decision regret. The impact of patient education on LOS has not been examined in breast reconstruction; however, there are minimal risks associated with this intervention. Consequently, we strongly recommend ERAS protocols in breast reconstruction that incorporated preoperative education and counseling, ideally in a shared decision-making model (Grade 1B).

\section{Fasting, nutrition, and carbohydrate loading}

In two of the ERAS protocols for breast reconstruction, preoperative fasting from the intake of clear liquids for at least 2 hours prior to surgery was included in the treatment pathway, whereas one study recommended at least 3 hours of fasting. ${ }^{63,64,67}$ For decades, preoperative fasting was recommended with "NPO after midnight" in an effort to minimize the risk of pulmonary aspiration by decreasing gastric volume. ${ }^{78}$ However, over the last several years, this dogma has been challenged by a multitude of studies demonstrating preoperative fasting from the intake of clear fluids for 2 hours and from the intake of solids for 6 hours to be optimal. A 2017 meta-analysis of RCTs demonstrated a lower risk of aspiration for patients with clear liquid intake up to 2 hours prior to surgery versus traditional fasting ( $>4$ hours). ${ }^{79}$ Furthermore, prior systematic reviews concluded that preoperative fasting to 6 hours for solids is safe. ${ }^{80}$ The primary concern with prolonged fasting is exacerbation of the surgical stress response, which constitutes a coordinated reaction to surgical injury. ${ }^{27,81}$ Ultimately, prolonged catabolism from fasting combined with the surgical stress response can potentiate hyperglycemia, insulin resistance, hyperthermia, immunosuppression, and muscle loss in the perioperative period, potentially contributing to adverse outcomes and delayed recovery. ${ }^{26,27}$ Therefore, the goal with perioperative nutritional management is to mitigate these effects.

In addition to changing fasting guidelines, there is considerable evidence from meta-analyses, systematic reviews, and RCTs demonstrating the intake of carbohydrate-rich liquids, ie, carbohydrate loading, prior to elective surgery, reduces postoperative insulin resistance and hyperglycemia, minimizes muscle loss, and shortens LOS. ${ }^{79,80,82-88}$ Furthermore, several RCTs establish clear liquid intake and carbohydrate loading up to 2 hours before a procedure improves patients' subjective well-being by reducing thirst and hunger. ${ }^{79,80,86,89-91}$ Although there are no specific studies in breast reconstruction, evidence-based recommendations can be adapted from these studies in the elective surgical population.

Recommendation: We recommend minimizing preoperative fasting to only 2 hours for clear liquids and 6 hours for solids (Grade 1A). Furthermore, we recommend preoperative 
carbohydrate loading via oral liquid intake up to 2 hours prior to surgery to mitigate adverse effects associated with the surgical stress response (Grade 1A).

\section{Antimicrobial prophylaxis}

All ERAS protocols included preoperative antibiotic use. In breast reconstruction, evidence for perioperative antibiotics for the prevention of surgical site infection (SSI) is largely based on studies in the prosthetic population; data on antibiotic use in microvascular breast reconstruction are limited. A prior survey of members of the American Society for Reconstructive Microsurgery (ASRM) revealed consensus agreement regarding preoperative administration of antibiotics within 1 hour prior to microvascular breast reconstruction; however, no consensus was present on the optimal duration of antibiotic administration. ${ }^{92}$ The practice of administering preoperative antibiotics within 60 minutes of incision is supported by considerable high-quality evidence, albeit not specific to breast reconstruction, including a 2014 Cochrane review of RCTs, and recommended by major national organizations, including Centers for Disease Control and Prevention (CDC), the Surgical Care Improvement Project (SCIP), and the AHRQ. ${ }^{93-97}$ What is less clear is the optimal duration of antibiotics. SCIP and CDC guidelines recommend a short duration ( $<24$ hours) of prophylaxis. ${ }^{94,95,97}$ There are two retrospective studies comparing patients receiving 24 versus $>24$ hours of antimicrobial prophylaxis in microvascular breast reconstruction. ${ }^{98,99}$ These studies showed no reduction in overall incidence of SSI for patients receiving antibiotics $>24$ hours. This is also supported by systematic reviews regarding the duration of prophylactic antibiotic use in prosthetic breast reconstruction, which presumably has an equal or higher intrinsic risk of SSI due to the placement of an implant. ${ }^{100,101}$

One of the ERAS protocols included antiseptic bathing for antimicrobial prophylaxis. Preoperative bathing and postoperative bathing with skin antiseptics are often recommended in procedures involving the placement of a prosthesis; however, the prevalence of this practice is unclear. ${ }^{102-104} \mathrm{~A}$ 2015 Cochrane review and a 2017 meta-analysis separately confirmed that there is no clear evidence of benefit for showering/bathing with antiseptic solution compared to usual wash products prior to clean surgeries. ${ }^{105,106}$

Recommendation: All patients undergoing breast reconstruction should receive preoperative antibiotics within 1 hour of incision. There is no documented benefit to prolonged antimicrobial prophylaxis; therefore, we recommend adherence to SCIP and CDC guidelines for administering only 24 hours of antibiotics (Grade 1A). There is no proven benefit for preoperative showering/bathing with antiseptic solution; thus, we recommend patients follow usual bathing practices prior to surgery (Grade 1A).

\section{Intraoperative management \\ Preemptive analgesia and PVBs}

The management of postoperative pain with multimodal therapy is a key component of ERAS protocols. Multimodal protocols are presumed to be effective because they address different pain mechanisms to reduce acute postoperative pain, which may subsequently blunt the development of chronic pain. ${ }^{27,107}$ ERAS protocols for breast reconstruction incorporated preemptive analgesia with opioid (at the discretion of the anesthesia provider) and nonopioid combinations of regional anesthesia blocks (2/5 studies), nonsteroidal anti-inflammatory drugs (NSAIDs) (4/5 studies), acetaminophen (5/5 studies), and/or gabapentin (4/5 studies). Regional anesthesia techniques were previously discussed; NSAIDs, acetaminophen, and gabapentin are discussed in the postoperative management section. Local anesthetic techniques utilizing continuous infusion pain catheters and regional anesthetic techniques utilizing peripheral nerve blocks are described in the literature. A metaanalysis in 2013 demonstrated local anesthetic pain catheters at the donor site, either on top of the rectus sheath or under the rectus fascia, significantly decreased opioid use but only showed a trend toward reducing LOS, for patients undergoing microvascular breast reconstruction (MBR). ${ }^{108}$ Furthermore, two RCTs confirmed that continuous infusion catheters have no deleterious effect on flap perfusion or complications. ${ }^{109,110}$

Recommendation: There is moderate quality evidence to support the inclusion of local anesthetic techniques and preemptive analgesia in breast reconstruction (Grade 1B).

\section{Perioperative hemodynamics: fluid management, vasopressors, and allogenic blood transfusions}

Perioperative hemodynamics is more relevant to microvascular breast reconstruction compared to prosthetic breast reconstruction. The goal of perioperative hemodynamic management in microvascular breast reconstruction is to maintain tissue perfusion and optimize blood flow for the flap. ${ }^{111} \mathrm{~A}$ majority of microsurgeons agree that avoiding intraoperative hypotension, often considered as a mean arterial pressure (MAP) of $<65 \mathrm{mmHg}$, is critical to flap success and prefer some combination of intravenous fluids, blood products, and vasopressors to achieve this. ${ }^{112}$ Our understanding of fluid management has evolved recently, and most ERAS protocols advocate for either a balanced fluid approach (emphasizing euvolemia, minimal weight changes, and maintenance of 
normal physiology and homeostasis) or a goal-directed fluid therapy (GDFT) (emphasizing optimal cardiac output and oxygen delivery to tissues to prevent hypoperfusion). ${ }^{113}$ In microvascular breast reconstruction, there is evidence to support a focus on maintenance of a zero, or near zero, fluid balance. Data from two retrospective studies demonstrate that excessive underresuscitation contributes to an increased risk for adverse flap events. ${ }^{14,115}$ Similarly, retrospective studies have shown liberal fluid resuscitation or fluid overload increases flap complications in both breast reconstruction and other microvascular flap procedures. ${ }^{115-119}$ In the nonfree flap population, meta-analyses of RCTs reaffirm the value of balanced fluid therapy in reducing perioperative complications and LOS. ${ }^{120,121}$ There are no studies evaluating GDFT, which uses hemodynamic monitoring to guide fluid management, in microvascular breast reconstruction. However, multiple meta-analyses on GDFT in surgical patients demonstrate reductions in complications and LOS compared to standard or liberal fluid resuscitation models. ${ }^{122-129}$ There are no studies comparing GDFT with balanced fluid therapy.

Although vasopressors were initially presumed to have devastating effects on free flap success, recent evidence has not corroborated these fears. A 2014 systematic review of retrospective studies showed no consistent effects on flap perfusion or flap complications. ${ }^{130}$ Subsequent to that publication, a retrospective cohort study of 682 patients and 1039 flaps also failed to demonstrate an increased risk of thrombotic events or flap loss in patients receiving vasopressors. ${ }^{131}$

In contrast to vasopressors and a balanced fluid approach, there is evidence suggesting that perioperative allogenic red blood cell transfusions in microvascular breast reconstruction are associated with an increased rate of postoperative complications and additional resource utilization. Six retrospective studies, all published after 2011, concluded that perioperative transfusions increase postoperative complications, prolong LOS, and incur additional costs; therefore, restrictive transfusion strategies (avoid transfusions in patients with hemoglobin thresholds $>7 \mathrm{~g} / \mathrm{dL}$ ) are now advocated. ${ }^{132-138}$

Recommendation: Perioperative fluid management should follow principles of balanced fluid therapy or GDFT and avoid underresuscitation and/or fluid overload (Grade 1A). Vasopressors may be used as an adjunct to intravenous fluids to avoid intraoperative hypotension and maintain hemodynamic stability; to date, human clinical studies have not demonstrated adverse complications with vasopressor use in microvascular breast reconstruction, albeit the existing data are of low quality (Grade 2C). We recommend a restrictive strategy for allogenic transfusions to minimize postoperative complications and avoid prolonged LOS (Grade 1C).

\section{Minimally invasive operative techniques (in autologous breast reconstruction)}

\section{Muscle-sparing procedures (donor-site)}

Minimizing the invasiveness of surgical procedures is a key component of ERAS protocols in different specialties. All patients treated in the included ERAS protocols for microvascular breast reconstruction underwent either a unilateral procedure or a bilateral procedure utilizing free TRAM (FTRAM), muscle-sparing TRAM (MS-TRAM), or DIEP flaps; there were no superficial inferior epigastric artery (SIEA) flaps reported. SIEA and DIEP flaps, which theoretically preserve the abdominal wall, would constitute the spectrum of "minimally invasive" surgery when compared with FTRAM or MS-TRAM flaps or pedicled flaps in autologous breast reconstruction. In regard to acute recovery, a majority of the data compares DIEP flaps with TRAM flaps (with MSTRAM and FTRAM often combined into one group). There are three retrospective studies demonstrating that mean LOS is shorter in patients undergoing DIEP flaps than in patients undergoing TRAM flaps. ${ }^{139-141}$ There is also a single prospective cohort study demonstrating significantly shorter LOS for SIEA flaps compared with DIEP flaps; however, this study is limited by inadequate sample size and the lack of control for comorbidities. ${ }^{142}$ In regard to long-term postoperative function, there are multiple meta-analyses of nonrandomized observational studies comparing donor-site morbidity and abdominal wall function in patients undergoing MBR with DIEP, SIEA, or TRAM flaps. ${ }^{143-146}$ These studies demonstrate that SIEA and DIEP flaps reduce donor-site morbidity, including abdominal bulge or hernia, compared to TRAM flaps but may increase the risk of flap-related complications. However, there are several methodological limitations to the studies included in these meta-analyses, which make them highly susceptible to bias. Interestingly, a recent multicenter study in North America did not find significant differences in patient-reported outcomes of abdominal well-being or morbidity when comparing DIEP flaps with TRAM flaps. ${ }^{147}$

Recommendation: Surgeons must consider the benefits of potentially reduced abdominal wall morbidity against the potential risk of higher complications and the potential burdens of increased operative time and complexity associated with SIEA and DIEP flaps. We suggest autologous breast reconstruction be performed with DIEP flaps whenever feasible but acknowledge the decision to perform a SIEA, DIEP, 
MS-TRAM, FTRAM, or pedicled autologous flap, which is most often dictated by patients' anatomy and characteristics (Grade 2B).

\section{Rib-sparing techniques (recipient site)}

In addition to donor-site preservation, a less invasive approach to the recipient site is also advocated in the literature for microvascular breast reconstruction. The presumed benefit of a rib-sparing approach to internal mammary vessel harvest is diminished chest wall morbidity, whereas the presumed disadvantages are complexity in patients with narrow intercostal spaces and limited exposure, which may lead to operative complications. ${ }^{148}$ To date, there is lowquality evidence to support rib-sparing techniques. Seven retrospective studies have been published, most of which focus on the efficiency and safety of this technique. ${ }^{149-155}$ Due to substantial heterogeneity, comparison across studies is limited. Only three studies included a comparison group (costochondral segment removed) and two of these compared postoperative pain, both demonstrating significantly reduced pain with rib preservation. ${ }^{151,153,154}$ In regard to complications, most studies had no comparison group but reported a low incidence of complications in line with acceptable published standards for breast reconstruction; however, one study did find a significantly greater incidence of fat necrosis with a rib-sparing approach. ${ }^{154}$

Recommendation: There is low-quality evidence to support rib-sparing techniques in microvascular breast reconstruction, and substantial uncertainty is present in the estimates of benefits, risks, and burdens associated with this technique. Given this, we can only formulate a very weak recommendation that surgeons perform rib-sparing techniques in patients with suitably wide intercostal spaces; however, other alternatives may be equally reasonable (Grade 2C).

\section{Prevention of postoperative nausea and vomiting (PONV)}

Avoidance of PONV is frequently identified by patients as their top priority in the immediate postoperative recovery period; therefore, the American Society of Anesthesiologists (ASA) recommends prophylaxis for PONV, in addition to minimize opiate use, in the perioperative period. ${ }^{156-159}$ There are many agents with antiemetic effects; however, the best evidence supports 5-HT3 receptor antagonists (eg, ondansetron), dexamethasone, and transdermal scopolamine. Data from recent meta-analyses indicate that 5-HT3 receptor antagonists, dexamethasone, and scopolamine are independently effective at reducing PONV and the need for rescue antiemetics when administered prophylactically. ${ }^{159-161}$ There are also several RCTs, comparing combination prophylaxis with multiple agents versus single-agent prophylaxis that demonstrate a benefit to combination therapy; however, various combinations used and differences in patient populations precluded pooled analyses. ${ }^{159,162-166}$

Recommendation: We recommend pharmacological prophylaxis with a combination of antiemetic agents to prevent PONV and limit the need for rescue treatment (Grade 1A).

\section{Postoperative management} Postoperative analgesia

Minimizing the opiate use is an essential goal in any ERAS protocol. There is considerable support in the literature for incorporating NSAIDs, including intravenous ketorolac, into multimodal analgesia protocols. A Cochrane review of 72 RCTs demonstrated that NSAIDs significantly reduce postoperative pain compared to placebo. ${ }^{167}$ Data from three other meta-analyses also confirm NSAIDs, as a part of multimodal therapy, reduce postoperative pain, and minimize some adverse effects, including PONV, of opiates in the postoperative period. ${ }^{168-170}$ In regard to ketorolac, a metaanalysis of 13 RCTs in a diverse group of surgical patients found that ketorolac significantly reduced postoperative pain, opioid consumption, and PONV. ${ }^{171}$ Recently, Afonso et al ${ }^{63}$ demonstrated that the addition of intravenous ketorolac to liposomal bupivacaine TAP blocks significantly reduced opioid consumption compared to TAP blocks alone in patients undergoing microvascular breast reconstruction. These findings support a prior retrospective cohort study that found ketorolac, as an adjunct treatment, reducing opiate use in TRAM flap breast reconstruction. ${ }^{172}$ Additionally, bleeding concerns with the use of ketorolac are not substantiated by the literature, for either breast reconstruction or surgical procedures in general. ${ }^{63,170,172,173}$

In addition to NSAIDs, acetaminophen has been suggested as an adjunct to perioperative pain management protocols in breast reconstruction. A Cochrane review of 51 RCTs demonstrated that acetaminophen use, compared to placebo, significantly reduced postoperative pain in surgical patients. ${ }^{174}$ Furthermore, a recent systematic review concluded that a combination of acetaminophen and NSAIDs offers superior analgesia when compared with either drug alone, lending additional support to the concept of multimodal analgesia protocols. ${ }^{175}$

Similar to NSAIDs and acetaminophen, gabapentin is frequently included in ERAS protocols, with the presumed benefit being the inhibition of nociception and central 
sensitization. ${ }^{176}$ There are no studies evaluating the independent effect of gabapentin on postoperative pain in breast reconstruction; however, multiple meta-analyses indicate that gabapentin has both a significant analgesic and an opioid sparing effect in surgical patients. ${ }^{176-179}$

Recommendation: Minimizing the opiate use and postoperative pain is an essential goal of multimodal perioperative care protocols. While minimal direct evidence exists in breast reconstruction, sufficient high-quality evidence may be extrapolated to support the inclusion of NSAIDs (ie, ketorolac), acetaminophen, and gabapentin in ERAS protocols to reduce postoperative pain and opiate use (Grade 1A).

\section{Early ambulation and functional recovery}

All of the ERAS protocols included ambulation as a criterion for discharge, with early mobilization at postoperative day (POD) 1 emphasized. There are no studies that evaluate the independent impact of early ambulation on postoperative outcomes in breast reconstruction and limited studies in the broader surgical literature. A recent systematic review concluded that there may be some benefit to accelerate bowel function and reduce hospital LOS with early mobilization in the abdominal and thoracic surgical populations; however, the poor methodological quality of included studies and inconsistencies in reporting of outcomes made it difficult to draw any firm conclusions. ${ }^{180}$ The primary proposed benefit for early mobilization is the absence of prolonged immobilization, which is known to be associated with adverse events, including venous thromboembolism, pulmonary deconditioning, and muscle weakness. ${ }^{181,182}$ The risks of early ambulation are unclear. If patients avoid significant flexion/extension at the waist, it is hard to identify a theoretical premise for how early ambulation would potentiate flap or donor-site complications in abdominally based autologous breast reconstruction. Furthermore, the only burden of early mobilization is the requirement for physical therapy or nursing assistance until patients can ambulate independently; however, this requirement is likely present regardless of the date of ambulation.

Recommendation: We recommend early ambulation be included in ERAS protocols for breast reconstruction. While there is a lack of high-quality evidence, the potential benefits appear to outweigh the risks and burdens for early mobilization (Grade 1C).

\section{Timing of urinary catheter removal}

Urinary catheter placement is significantly more common for lengthy autologous breast reconstruction procedures compared to prosthetic procedures. In microvascular breast reconstruction, all patients typically require urinary catheterization, given the length of surgery and need for resuscitative monitoring. The timing of catheter removal was a focus in the published ERAS protocols for microvascular breast reconstruction, with all including removal of urinary catheters at POD 1 as a protocol item. There is high-quality evidence, including meta-analyses and RCTs, from the nonmicrovascular surgical literature to support this practice. In general, these studies have found lower rates of catheter-associated urinary tract infections and no significantly increased risk of recatheterization in patients who had early (POD 1) catheter removal. ${ }^{183-185}$

Recommendation: We recommend the removal of urinary catheters by POD 1, at the latest, in all patients undergoing breast reconstruction who do not require resuscitative monitoring (Grade 1A).

\section{Timing of postoperative nutrition}

Similar to the concepts of early mobilization and early removal of urinary catheters, surgeons in various disciplines have recommended early postoperative oral feeding (within 24 hours of surgery) to enhance recovery by facilitating return to normal functioning. Traditionally, patients undergoing prosthetic breast reconstruction were advanced to clear liquids and then a regular diet as tolerated immediately after surgery whereas patients undergoing microvascular breast reconstruction were kept NPO for at least 24 hours as a precaution in case where emergent return to the operating room was necessary. As detailed earlier, fasting from oral liquids does not alter anesthetic risks. Furthermore, given the low rate of flap complications requiring immediate take back, this practice of delayed oral intake is unnecessary. Although no direct evidence exists in breast reconstruction, there is considerable evidence from the broader surgical literature that early postoperative oral feeding is beneficial. Two recent meta-analyses, a 2014 Cochrane review of RCTs in abdominal gynecological surgery and a 2016 meta-analysis of 15 studies in gastrointestinal surgery, showed that early feeding was associated with shorter LOS, higher satisfaction, and no increase in complications when compared with traditional timing. ${ }^{186,187}$

Recommendation: For prosthetic reconstruction, we recommend advancing patients' diets as tolerated on POD 0. For microvascular breast reconstruction, we recommend postoperative oral feeding with clear liquids commencing immediately postoperatively (POD 0 ), with intake guided by 
patient preference and comfort. In patients tolerating clear liquid intake, we advocate advancement to a regular diet on POD 1 (Grade 1B).

\section{Discussion and future directions}

Increasing health care costs have led to significant health care reforms and the advent of value-based and alternative payment models that incentivize value, efficiency, and quality in patient care. ${ }^{22,188}$ In these new paradigms, it is critical to provide high-quality care while minimizing resource utilization during an episode of care. In response, ERAS protocols have been proposed as potential strategies to improve the overall value of surgical care. While widely utilized in various surgical disciplines, few studies have evaluated ERAS protocols in breast reconstruction. ${ }^{64}$ In this study, we comprehensively reviewed the literature on ERAS protocols for breast reconstruction and provided evidence-based recommendations for each perioperative intervention included in these protocols.

Although it is promising to start to find ERAS protocols utilized in breast reconstruction, there remains a paucity of high-quality evidence on the impact of these protocols. To date, only five retrospective studies have been published on ERAS protocols in breast reconstruction and there is a significant heterogeneity between these studies in regard to perioperative interventions included, patient groups, comorbidities reported, and outcomes measured. There is a substantial need for additional research endeavors on this topic. It is important that future efforts to develop and implement ERAS protocols in breast reconstruction follow evidence-based guidelines in development and clearly report the components of the protocol. Future RCTs or high-quality prospective cohort studies are a priority. For studies following a nonrandomized observational design, patient and treatment covariates should be reported and controlled for analytically. Furthermore, studies should report clinically meaningful outcomes in a standardized way to facilitate comparison. All studies should, at minimum, report LOS, postoperative opiate use, and patient-reported outcomes using validated measures, including QoR and health-related quality of life (BREAST-Q). Additionally, studies examining the costeffectiveness of ERAS protocols in breast reconstruction are needed to demonstrate if this intervention has value to the health care system. Finally, it would be valuable for studies to identify barriers and enablers to protocol implementation and provide a detailed description of the implementation process. Understanding these elements would allow different institutions to adapt evidence-based protocols to their local environment.

\section{Conclusion}

Optimizing the perioperative management of patients undergoing microvascular breast reconstruction by implementing ERAS protocols has the potential to improve postoperative pain control, enhance patient-centered outcomes, accelerate recovery, and minimize health care resource utilization. Institutions and surgeons aiming to optimize perioperative care in MBR should incorporate evidence-based interventions in the development of future ERAS protocols. Ultimately, following evidence-based recommendations, as delineated in this study, is integral to develop and implement treatment protocols with external validity that improve the quality and value of patient care.

\section{Acknowledgments}

RPP is supported by a National Institutes of Health (NIH) Ruth L Kirschstein National Research Service Award Institutional Research Training Grant (T32CA190194), the Foundation for Barnes-Jewish Hospital, and a National Cancer Institute Cancer Center Support Grant to Siteman Cancer Center (P30 CA091842). The content is solely the responsibility of the authors and does not necessarily represent the official view of the NIH.

\section{Disclosure}

The authors report no conflicts of interest in this work.

\section{References}

1. Eltahir Y, Werners LL, Dreise MM, et al. Quality-of-life outcomes between mastectomy alone and breast reconstruction: comparison of patient-reported BREAST-Q and other health-related quality-of-life measures. Plast Reconstr Surg. 2013;132(2):201e-209e.

2. Winters ZE, Benson JR, Pusic AL. A systematic review of the clinical evidence to guide treatment recommendations in breast reconstruction based on patient-reported outcome measures and health-related quality of life. Ann Surg. 2010;252(6):929-942.

3. Matros E, Albornoz CR, Razdan SN, et al. Cost-effectiveness analysis of implants versus autologous perforator flaps using the BREAST-Q. Plast Reconstr Surg. 2015;135(4):937-946.

4. Hu ES, Pusic AL, Waljee JF, et al. Patient-reported aesthetic satisfaction with breast reconstruction during the long-term survivorship period. Plast Reconstr Surg. 2009;124(1):1-8.

5. Yueh JH, Slavin SA, Adesiyun T, et al. Patient satisfaction in postmastectomy breast reconstruction: a comparative evaluation of DIEP, TRAM, latissimus flap, and implant techniques. Plast Reconstr Surg. 2010;125(6):1585-1595.

6. Lee KT, Mun GH. Prosthetic breast reconstruction in previously irradiated breasts: a meta-analysis. J Surg Oncol. 2015;112(5):468-475.

7. Pusic AL, Matros E, Fine N, et al. Patient-reported outcomes 1 year after immediate breast reconstruction: results of the mastectomy reconstruction outcomes consortium study. J Clin Oncol. 2017;35(22):2499-2506.

8. Hickey OT, Nugent NF, Burke SM, Hafeez P, Mudrakouski AL, Shorten GD. Persistent pain after mastectomy with reconstruction. J Clin Anesth. 2011;23(6):482-488. 
9. Vadivelu N, Schreck M, Lopez J, Kodumudi G, Narayan D. Pain after mastectomy and breast reconstruction. Am Surg. 2008;74(4):285-296.

10. Hickey OT, Burke SM, Hafeez P, Mudrakouski AL, Hayes ID, Shorten GD. Severity of acute pain after breast surgery is associated with the likelihood of subsequently developing persistent pain. Clin J Pain. 2010;26(7):556-560.

11. Elmore L, Myckatyn TM, Gao F, et al. Reconstruction patterns in a single institution cohort of women undergoing mastectomy for breast cancer. Ann Surg Oncol. 2012;19(10):3223-3229.

12. Wallace MS, Wallace AM, Lee J, Dobke MK. Pain after breast surgery: a survey of 282 women. Pain. 1996;66(2-3):195-205.

13. Clarke H, Soneji N, Ko DT, Yun L, Wijeysundera DN. Rates and risk factors for prolonged opioid use after major surgery: population based cohort study. BMJ. 2014;348:g1251.

14. Waljee JF, Li L, Brummett CM, Englesbe MJ. Iatrogenic opioid dependence in the United States: are surgeons the gatekeepers? Ann Surg. 2016;265(4):728-730.

15. Berg K, Kjellgren K, Unosson M, Arestedt K. Postoperative recovery and its association with health-related quality of life among day surgery patients. BMC Nurs. 2012;11(1):24.

16. Joshi GP, Ogunnaike BO. Consequences of inadequate postoperative pain relief and chronic persistent postoperative pain. Anesthesiol Clin North America. 2005;23(1):21-36.

17. Wu CL, Richman JM. Postoperative pain and quality of recovery. Curr Opin Anaesthesiol. 2004;17(5):455-460.

18. Myles PS, Hunt JO, Nightingale CE, et al. Development and psychometric testing of a quality of recovery score after general anesthesia and surgery in adults. Anesth Analg. 1999;88(1):83-90.

19. Coley KC, Williams BA, DaPos SV, Chen C, Smith RB. Retrospective evaluation of unanticipated admissions and readmissions after same day surgery and associated costs. J Clin Anesth. 2002;14(5):349-353.

20. Conway PH. Value-driven health care: implications for hospitals and hospitalists. J Hosp Med. 2009;4(8):507-511.

21. Miller HD. From volume to value: better ways to pay for health care. Health Aff (Millwood). 2009;28(5):1418-1428.

22. Porter ME. What is value in health care? NEngl J Med. 2010;363(26): 2477-2481.

23. Lee L, Li C, Landry T, et al. A systematic review of economic evaluations of enhanced recovery pathways for colorectal surgery. Ann Surg. 2014;259(4):670-676.

24. Thiele RH, Rea KM, Turrentine FE, et al. Standardization of care: impact of an enhanced recovery protocol on length of stay, complications, and direct costs after colorectal surgery. J Am Coll Surg. 2015;220(4):430-443.

25. Shewale JB, Correa AM, Baker CM, et al; University of Texas MD Anderson Esophageal Cancer Collaborative Group. Impact of a fasttrack esophagectomy protocol on esophageal cancer patient outcomes and hospital charges. Ann Surg. 2015;261(6):1114-1123.

26. Wilmore DW. From Cuthbertson to fast-track surgery: 70 years of progress in reducing stress in surgical patients. Ann Surg. 2002;236(5):643-648.

27. Kehlet H, Dahl JB. Anaesthesia, surgery, and challenges in postoperative recovery. Lancet. 2003;362(9399):1921-1928.

28. Kehlet H, Jorgensen CC. Advancing surgical outcomes research and quality improvement within an enhanced recovery program framework. Ann Surg. 2016;264(2):237-238.

29. Arsalani-Zadeh R, ElFadl D, Yassin N, MacFie J. Evidence-based review of enhancing postoperative recovery after breast surgery. $\mathrm{Br} J$ Surg. 2011;98(2):181-196.

30. Moher D, Liberati A, Tetzlaff J, Altman DG. Preferred reporting items for systematic reviews and meta-analyses: the PRISMA statement. PLoS Med. 2009;6(7):e1000097.

31. Stroup DF, Berlin JA, Morton SC, et al. Meta-analysis of observational studies in epidemiology: a proposal for reporting. Meta-analysis Of Observational Studies in Epidemiology (MOOSE) group. JAMA. 2000;283(15):2008-2012.
32. Guyatt GH, Oxman AD, Vist GE, et al; GRADE Working Group. GRADE: an emerging consensus on rating quality of evidence and strength of recommendations. BMJ. 2008;336(7650):924-926.

33. Guyatt GH, Oxman AD, Kunz R, et al; GRADE Working Group. Going from evidence to recommendations. BMJ. 2008;336(7652):1049-1051.

34. Guyatt G, Gutterman D, Baumann MH, et al. Grading strength of recommendations and quality of evidence in clinical guidelines: report from an American College of Chest Physicians task force. Chest. 2006;129(1):174-181.

35. Ariyan S, Martin J, Lal A, et al. Antibiotic prophylaxis for preventing surgical-site infection in plastic surgery: an evidence-based consensus conference statement from the American Association of Plastic Surgeons. Plast Reconstr Surg. 2015;135(6):1723-1739.

36. Pannucci CJ, MacDonald JK, Ariyan S, et al. Benefits and risks of prophylaxis for deep venous thrombosis and pulmonary embolus in plastic surgery: a systematic review and meta-analysis of controlled trials and consensus conference. Plast Reconstr Surg. 2016;137(2):709-730.

37. Higgins JPT, Green S, editors. Cochrane Handbook for Systematic Reviews of Interventions Version 5.1.0 [updated March 2011]. The Cochrane Collaboration, 2011.

38. Guyatt GH, Oxman AD, Schunemann HJ, Tugwell P, Knottnerus A. GRADE guidelines: a new series of articles in the Journal of Clinical Epidemiology. J Clin Epidemiol. 2011;64(4):380-382.

39. Balshem H, Helfand M, Schunemann HJ, et al. GRADE guidelines: 3 Rating the quality of evidence. J Clin Epidemiol. 2011;64(4):401-406.

40. Guyatt G, Oxman AD, Akl EA, et al. GRADE guidelines: 1. Introduction-GRADE evidence profiles and summary of findings tables. J Clin Epidemiol. 2011;64(4):383-394.

41. Kumar K, Kirksey MA, Duong S, Wu CL. A review of opioid-sparing modalities in perioperative pain management: methods to decrease opioid use postoperatively. Anesth Analg. 2017;125(5):1749-1760.

42. Baxter R, Bramlett K, Onel E, Daniels S. Impact of local administration of liposome bupivacaine for postsurgical analgesia on wound healing: a review of data from ten prospective, controlled clinical studies. Clin Ther. 2013;35(3):312-320.e5.

43. Vyas KS, Rajendran S, Morrison SD, et al. Systematic review of liposomal bupivacaine (exparel) for postoperative analgesia. Plast Reconstr Surg. 2016;138(4):748e-756e.

44. Rafi AN. Abdominal field block: a new approach via the lumbar triangle. Anaesthesia. 2001;56(10):1024-1026.

45. Charlton S, Cyna AM, Middleton P, Griffiths JD. Perioperative transversus abdominis plane (TAP) blocks for analgesia after abdominal surgery. Cochrane Database Syst Rev. 2010;12:CD007705.

46. Hivelin M, Wyniecki A, Plaud B, Marty J, Lantieri L. Ultrasoundguided bilateral transversus abdominis plane block for postoperative analgesia after breast reconstruction by DIEP flap. Plast Reconstr Surg. 2011;128(1):44-55.

47. Zhong T, Ojha M, Bagher S, et al. Transversus abdominis plane block reduces morphine consumption in the early postoperative period following microsurgical abdominal tissue breast reconstruction: a double-blind, placebo-controlled, randomized trial. Plast Reconstr Surg. 2014;134(5):870-878.

48. Zhong $\mathrm{T}$, Wong $\mathrm{KW}$, Cheng $\mathrm{H}$, et al. Transversus abdominis plane (TAP) catheters inserted under direct vision in the donor site following free DIEP and MS-TRAM breast reconstruction: a prospective cohort study of 45 patients. J Plast Reconstr Aesthet Surg. 2013;66(3):329-336.

49. Wheble GA, Tan EK, Turner M, Durrant CA, Heppell S. Surgeonadministered, intra-operative transversus abdominis plane block in autologous breast reconstruction: a UK hospital experience. J Plast Reconstr Aesthet Surg. 2013;66(12):1665-1670.

50. Jablonka EM, Lamelas AM, Kim JN, et al. Transversus abdominis plane blocks with single-dose liposomal bupivacaine in conjunction with a nonnarcotic pain regimen help reduce length of stay following abdominally based microsurgical breast reconstruction. Plast Reconstr Surg. 2017;140(2):240-251. 
51. Rozen WM, Tran TM, Ashton MW, Barrington MJ, Ivanusic JJ, Taylor GI. Refining the course of the thoracolumbar nerves: a new understanding of the innervation of the anterior abdominal wall. Clin Anat. 2008;21(4):325-333.

52. Jankovic ZB, du Feu FM, McConnell P. An anatomical study of the transversus abdominis plane block: location of the lumbar triangle of Petit and adjacent nerves. Anesth Analg. 2009;109(3): 981-985.

53. Schnabel A, Reichl SU, Kranke P, Pogatzki-Zahn EM, Zahn PK. Efficacy and safety of paravertebral blocks in breast surgery: a meta-analysis of randomized controlled trials. Br J Anaesth. 2010;105(6):842-852.

54. Parikh RP, Sharma K, Guffey R, Myckatyn TM. Preoperative paravertebral block improves postoperative pain control and reduces hospital length of stay in patients undergoing autologous breast reconstruction after mastectomy for breast cancer. Ann Surg Oncol. 2016;23(13):4262-4269.

55. Odom EB, Mehta N, Parikh RP, Guffey R, Myckatyn TM. Paravertebral blocks reduce narcotic use without affecting perfusion in patients undergoing autologous breast reconstruction. Ann Surg Oncol. 2017;24(11):3180-3187.

56. Unkart JT, Padwal JA, Ilfeld BM, Wallace AM. Treatment of postlatissimus dorsi flap breast reconstruction pain with continuous paravertebral nerve blocks: a retrospective review. Anesth Pain Med. 2016;6(5):e39476.

57. Coopey SB, Specht MC, Warren L, Smith BL, Winograd JM, Fleischmann K. Use of preoperative paravertebral block decreases length of stay in patients undergoing mastectomy plus immediate reconstruction. Ann Surg Oncol. 2013;20(4):1282-1286.

58. Fahy AS, Jakub JW, Dy BM, et al. Paravertebral blocks in patients undergoing mastectomy with or without immediate reconstruction provides improved pain control and decreased postoperative nausea and vomiting. Ann Surg Oncol. 2014;21(10):3284-3289.

59. Glissmeyer C, Johnson W, Sherman B, Glissmeyer M, Garreau J, Johnson N. Effect of paravertebral nerve blocks on narcotic use after mastectomy with reconstruction. Am J Surg. 2015;209(5):881-883.

60. Wolf O, Clemens MW, Purugganan RV, et al. A prospective, randomized, controlled trial of paravertebral block versus general anesthesia alone for prosthetic breast reconstruction. Plast Reconstr Surg. 2016;137(4):660e-666e.

61. Pace MM, Sharma B, Anderson-Dam J, Fleischmann K, Warren L, Stefanovich P. Ultrasound-guided thoracic paravertebral blockade: a retrospective study of the incidence of complications. Anesth Analg. 2016;122(4):1186-1191.

62. Krediet AC, Moayeri N, van Geffen GJ, et al. Different approaches to ultrasound-guided thoracic paravertebral block: an illustrated review. Anesthesiology. 2015;123(2):459-474.

63. Afonso A, Oskar S, Tan KS, et al. Is enhanced recovery the new standard of care in microsurgical breast reconstruction? Plast Reconstr Surg. 2017;139(5):1053-1061.

64. Batdorf NJ, Lemaine V, Lovely JK, et al. Enhanced recovery after surgery in microvascular breast reconstruction. J Plast Reconstr Aesthet Surg. 2015;68(3):395-402.

65. Bonde C, Khorasani H, Eriksen K, Wolthers M, Kehlet H, Elberg J. Introducing the fast track surgery principles can reduce length of stay after autologous breast reconstruction using free flaps: a case control study. J Plast Surg Hand Surg. 2015;49(6):367-371.

66. Bonde CT, Khorasani H, Elberg J, Kehlet H. Perioperative optimization of autologous breast reconstruction. Plast Reconstr Surg. 2016;137(2):411-414.

67. Dumestre DO, Webb CE, Temple-Oberle C. Improved recovery experience achieved for women undergoing implant-based breast reconstruction using an enhanced recovery after surgery model. Plast Reconstr Surg. 2017;139(3):550-559.

68. Barry MJ, Edgman-Levitan S. Shared decision making - pinnacle of patient-centered care. N Engl J Med. 2012;366(9):780-781.
69. Braddock CH 3rd, Edwards KA, Hasenberg NM, Laidley TL, Levinson W. Informed decision making in outpatient practice: time to get back to basics. JAMA. 1999;282(24):2313-2320.

70. Cohen WA, Ballard TN, Hamill JB, et al. Understanding and optimizing the patient experience in breast reconstruction. Ann Plast Surg. 2016;77(2):237-241.

71. Ho AL, Klassen AF, Cano S, Scott AM, Pusic AL. Optimizing patientcentered care in breast reconstruction: the importance of preoperative information and patient-physician communication. Plast Reconstr Surg. 2013;132(2):212e-220e.

72. Liu C, Zhuang Y, Momeni A, et al. Quality of life and patient satisfaction after microsurgical abdominal flap versus staged expander/implant breast reconstruction: a critical study of unilateral immediate breast reconstruction using patient-reported outcomes instrument BREASTQ. Breast Cancer Res Treat. 2014;146(1):117-126.

73. Sheehan J, Sherman KA, Lam T, Boyages J. Association of information satisfaction, psychological distress and monitoring coping style with post-decision regret following breast reconstruction. Psychooncology. 2007;16(4):342-351.

74. Zhong T, Hu J, Bagher S, et al. Decision regret following breast reconstruction: the role of self-efficacy and satisfaction with information in the preoperative period. Plast Reconstr Surg. 2013;132(5):724e-734e.

75. Aarts MA, Okrainec A, Glicksman A, Pearsall E, Victor JC, McLeod RS. Adoption of enhanced recovery after surgery (ERAS) strategies for colorectal surgery at academic teaching hospitals and impact on total length of hospital stay. Surg Endosc. 2012;26(2):442-450.

76. Forsmo HM, Pfeffer F, Rasdal A, Sintonen H, Korner H, Erichsen C. Pre- and postoperative stoma education and guidance within an enhanced recovery after surgery (ERAS) programme reduces length of hospital stay in colorectal surgery. Int J Surg. 2016;36(pt A): 121-126.

77. Younis J, Salerno G, Fanto D, Hadjipavlou M, Chellar D, Trickett JP. Focused preoperative patient stoma education, prior to ileostomy formation after anterior resection, contributes to a reduction in delayed discharge within the enhanced recovery programme. Int J Colorectal Dis. 2012;27(1):43-47.

78. Maltby JR. Fasting from midnight - the history behind the dogma. Best Pract Res Clin Anaesthesiol. 2006;20(3):363-378.

79. Practice guidelines for preoperative fasting and the use of pharmacologic agents to reduce the risk of pulmonary aspiration: application to healthy patients undergoing elective procedures: an updated report by the American Society of Anesthesiologists task force on preoperative fasting and the use of pharmacologic agents to reduce the risk of pulmonary aspiration. Anesthesiology. 2017;126(3):376-393.

80. Brady M, Kinn S, Stuart P. Preoperative fasting for adults to prevent perioperative complications. Cochrane Database Syst Rev. 2003;4:CD004423.

81. Blomqvist L, Malm M, Berg A, Svelander L, Kleinau S. The inflammatory reaction in elective flap surgery. Plast Reconstr Surg. 1998;101(6): 1524-1528.

82. Lambert E, Carey S. Practice guideline recommendations on perioperative fasting: a systematic review. JPEN J Parenter Enteral Nutr. 2016;40(8):1158-1165.

83. Li L, Wang Z, Ying X, et al. Preoperative carbohydrate loading for elective surgery: a systematic review and meta-analysis. Surg Today. 2012;42(7):613-624.

84. Noblett SE, Watson DS, Huong H, Davison B, Hainsworth PJ, Horgan AF. Pre-operative oral carbohydrate loading in colorectal surgery: a randomized controlled trial. Colorectal Dis. 2006;8(7):563-569.

85. Smith I, Kranke P, Murat I, et al; European Society of Anaesthesiology. Perioperative fasting in adults and children: guidelines from the European Society of Anaesthesiology. Eur J Anaesthesiol. 2011;28(8):556-569.

86. Smith MD, McCall J, Plank L, Herbison GP, Soop M, Nygren J. Preoperative carbohydrate treatment for enhancing recovery after elective surgery. Cochrane Database Syst Rev. 2014;8:CD009161. 
87. Yagci G, Can MF, Ozturk E, et al. Effects of preoperative carbohydrate loading on glucose metabolism and gastric contents in patients undergoing moderate surgery: a randomized, controlled trial. Nutrition. 2008;24(3):212-216.

88. Yuill KA, Richardson RA, Davidson HI, Garden OJ, Parks RW. The administration of an oral carbohydrate-containing fluid prior to major elective upper-gastrointestinal surgery preserves skeletal muscle mass postoperatively - a randomised clinical trial. Clin Nutr. 2005;24(1):32-37.

89. Gilbert SS, Easy WR, Fitch WW. The effect of pre-operative oral fluids on morbidity following anaesthesia for minor surgery. Anaesthesia. 1995;50(1):79-81.

90. Goodwin AP, Rowe WL, Ogg TW, Samaan A. Oral fluids prior to day surgery. The effect of shortening the pre-operative fluid fast on postoperative morbidity. Anaesthesia. 1991;46(12):1066-1068.

91. Wang ZG, Wang Q, Wang WJ, Qin HL. Randomized clinical trial to compare the effects of preoperative oral carbohydrate versus placebo on insulin resistance after colorectal surgery. Br J Surg. 2010;97(3): 317-327.

92. Reiffel AJ, Kamdar MR, Kadouch DJ, Rohde CH, Spector JA. Perioperative antibiotics in the setting of microvascular free tissue transfer: current practices. J Reconstr Microsurg. 2010;26(6):401-407.

93. Jones DJ, Bunn F, Bell-Syer SV. Prophylactic antibiotics to prevent surgical site infection after breast cancer surgery. Cochrane Database Syst Rev. 2014;3:CD005360.

94. Bratzler DW, Dellinger EP, Olsen KM, et al; American Society of Health-System Pharmacists; Infectious Disease Society of America; Surgical Infection Society; Society for Healthcare Epidemiology of America. Clinical practice guidelines for antimicrobial prophylaxis in surgery. Am J Health Syst Pharm. 2013;70(3):195-283.

95. Bratzler DW, Houck PM; Surgical Infection Prevention Guideline Writers Workgroup. Antimicrobial prophylaxis for surgery: an advisory statement from the National Surgical Infection Prevention Project. Am J Surg. 2005;189(4):395-404.

96. Dellinger EP, Gross PA, Barrett TL, et al. Quality standard for antimicrobial prophylaxis in surgical procedures. Infectious Diseases Society of America. Clin Infect Dis. 1994;18(3):422-427.

97. Mangram AJ, Horan TC, Pearson ML, Silver LC, Jarvis WR. Guideline for prevention of surgical site infection, 1999. Hospital Infection Control Practices Advisory Committee. Infect Control Hosp Epidemiol. 1999;20(4):250-278; quiz 279-280.

98. Drury KE, Lanier ST, Khavanin N, et al. Impact of postoperative antibiotic prophylaxis duration on surgical site infections in autologous breast reconstruction. Ann Plast Surg. 2016;76(2):174-179.

99. Liu DZ, Dubbins JA, Louie O, Said HK, Neligan PC, Mathes DW. Duration of antibiotics after microsurgical breast reconstruction does not change surgical infection rate. Plast Reconstr Surg. 2012;129(2):362-367.

100. Phillips BT, Halvorson EG. Antibiotic prophylaxis following implantbased breast reconstruction: what is the evidence? Plast Reconstr Surg. 2016;138(4):751-757.

101. Wang F, Chin R, Piper M, Esserman L, Sbitany H. Do prolonged prophylactic antibiotics reduce the incidence of surgical-site infections in immediate prosthetic breast reconstruction? Plast Reconstr Surg. 2016;138(6):1141-1149.

102. Brahmbhatt RD, Huebner M, Scow JS, et al. National practice patterns in preoperative and postoperative antibiotic prophylaxis in breast procedures requiring drains: survey of the American Society of Breast Surgeons. Ann Surg Oncol. 2012;19(10):3205-3211.

103. Craft RO, Damjanovic B, Colwell AS. Evidence-based protocol for infection control in immediate implant-based breast reconstruction. Ann Plast Surg. 2012;69(4):446-450.

104. Gowda AU, Chopra K, Brown EN, Slezak S, Rasko Y. Preventing breast implant contamination in breast reconstruction: a national survey of current practice. Ann Plast Surg. 2017;78(2):153-156.

105. Franco LM, Cota GF, Pinto TS, Ercole FF. Preoperative bathing of the surgical site with chlorhexidine for infection prevention: systematic review with meta-analysis. Am J Infect Control. 2017;45(4):343-349.
106. Webster J, Osborne S. Preoperative bathing or showering with skin antiseptics to prevent surgical site infection. Cochrane Database Syst Rev. 2015;2:CD004985.

107. Moiniche S, Kehlet H, Dahl JB. A qualitative and quantitative systematic review of preemptive analgesia for postoperative pain relief: the role of timing of analgesia. Anesthesiology. 2002;96(3):725-741.

108. Giordano S, Verajankorva E, Koskivuo I, Suominen E. Effectiveness of local anaesthetic pain catheters for abdominal donor site analgesia in patients undergoing free lower abdominal flap breast reconstruction: a meta-analysis of comparative studies. J Plast Surg Hand Surg. 2013;47(6):428-433.

109. Heller L, Kowalski AM, Wei C, Butler CE. Prospective, randomized, double-blind trial of local anesthetic infusion and intravenous narcotic patient-controlled anesthesia pump for pain management after free TRAM flap breast reconstruction. Plast Reconstr Surg. 2008;122(4):1010-1018.

110. Dagtekin O, Hotz A, Kampe S, Auweiler M, Warm M. Postoperative analgesia and flap perfusion after pedicled TRAM flap reconstruction - continuous wound instillation with ropivacaine $0.2 \%$. A pilot study. J Plast Reconstr Aesthet Surg. 2009;62(5):618-625.

111. Hagau N, Longrois D. Anesthesia for free vascularized tissue transfer. Microsurgery. 2009;29(2):161-167.

112. Vyas K, Wong L. Intraoperative management of free flaps: current practice. Ann Plast Surg. 2014;72(6):S220-S223.

113. Thiele RH, Raghunathan K, Brudney CS, et al; Perioperative Quality Initiative (POQI) I Workgroup. American Society for Enhanced Recovery (ASER) and Perioperative Quality Initiative (POQI) joint consensus statement on perioperative fluid management within an enhanced recovery pathway for colorectal surgery. Perioper Med (Lond). 2016;5:24.

114. Nelson JA, Fischer JP, Grover R, et al. Intraoperative perfusion management impacts postoperative outcomes: an analysis of 682 autologous breast reconstruction patients. J Plast Reconstr Aesthet Surg. 2015;68(2): 175-183.

115. Zhong T, Neinstein R, Massey C, et al. Intravenous fluid infusion rate in microsurgical breast reconstruction: important lessons learned from 354 free flaps. Plast Reconstr Surg. 2011;128(6):1153-1160.

116. Booi DI. Perioperative fluid overload increases anastomosis thrombosis in the free TRAM flap used for breast reconstruction. Eur J Plast Surg. 2011;34(2):81-86.

117. Clark JR, McCluskey SA, Hall F, et al. Predictors of morbidity following free flap reconstruction for cancer of the head and neck. Head Neck. 2007;29(12):1090-1101.

118. Haughey BH, Wilson E, Kluwe L, et al. Free flap reconstruction of the head and neck: analysis of 241 cases. Otolaryngol Head Neck Surg. 2001;125(1):10-17.

119. Patel RS, McCluskey SA, Goldstein DP, et al. Clinicopathologic and therapeutic risk factors for perioperative complications and prolonged hospital stay in free flap reconstruction of the head and neck. Head Neck. 2010;32(10):1345-1353.

120. Jia FJ, Yan QY, Sun Q, Tuxun T, Liu H, Shao L. Liberal versus restrictive fluid management in abdominal surgery: a meta-analysis. Surg Today. 2017;47(3):344-356.

121. Varadhan KK, Lobo DN. A meta-analysis of randomised controlled trials of intravenous fluid therapy in major elective open abdominal surgery: getting the balance right. Proc Nutr Soc. 2010;69(4): 488-498.

122. Berger MM, Gradwohl-Matis I, Brunauer A, Ulmer H, Dunser MW. Targets of perioperative fluid therapy and their effects on postoperative outcome: a systematic review and meta-analysis. Minerva Anestesiol. 2015;81(7):794-808.

123. Corcoran T, Rhodes JE, Clarke S, Myles PS, Ho KM. Perioperative fluid management strategies in major surgery: a stratified metaanalysis. Anesth Analg. 2012;114(3):640-651.

124. Giglio MT, Marucci M, Testini M, Brienza N. Goal-directed haemodynamic therapy and gastrointestinal complications in major surgery: a meta-analysis of randomized controlled trials. Br J Anaesth. 2009;103(5):637-646. 
125. Li P, Qu LP, Qi D, et al. Significance of perioperative goal-directed hemodynamic approach in preventing postoperative complications in patients after cardiac surgery: a meta-analysis and systematic review. Ann Med. 2017;49(4):343-351.

126. Ripolles-Melchor J, Espinosa A, Martinez-Hurtado E, et al. Perioperative goal-directed hemodynamic therapy in noncardiac surgery: a systematic review and meta-analysis. J Clin Anesth. 2016;28:105-115.

127. Rollins KE, Lobo DN. Intraoperative goal-directed fluid therapy in elective major abdominal surgery: a meta-analysis of randomized controlled trials. Ann Surg. 2016;263(3):465-476.

128. Som A, Maitra S, Bhattacharjee S, Baidya DK. Goal directed fluid therapy decreases postoperative morbidity but not mortality in major non-cardiac surgery: a meta-analysis and trial sequential analysis of randomized controlled trials. J Anesth. 2017;31(1):66-81.

129. Yuan J, Sun Y, Pan C, Li T. Goal-directed fluid therapy for reducing risk of surgical site infections following abdominal surgery - a systematic review and meta-analysis of randomized controlled trials. Int J Surg. 2017;39:74-87.

130. Ibrahim AM, Kim PS, Rabie AN, Lee BT, Lin SJ. Vasopressors and reconstructive flap perfusion: a review of the literature comparing the effects of various pharmacologic agents. Ann Plast Surg. 2014;73(2):245-248.

131. Nelson JA, Fischer JP, Grover R, et al. Intraoperative vasopressors and thrombotic complications in free flap breast reconstruction. J Plast Surg Hand Surg. 2017;51(5):336-341.

132. Appleton SE, Ngan A, Kent B, Morris SF. Risk factors influencing transfusion rates in DIEP flap breast reconstruction. Plast Reconstr Surg. 2011;127(5):1773-1782.

133. Fischer JP, Nelson JA, Au A, Tuggle CT 3rd, Serletti JM, Wu LC. Complications and morbidity following breast reconstruction - a review of 16,063 cases from the 2005-2010 NSQIP datasets. J Plast Surg Hand Surg. 2014;48(2):104-114.

134. Fischer JP, Nelson JA, Sieber B, et al. Transfusions in autologous breast reconstructions: an analysis of risk factors, complications, and cost. Ann Plast Surg. 2014;72(5):566-571.

135. Lee HK, Kim DH, Jin US, Jeon YT, Hwang JW, Park HP. Effect of perioperative transfusion of old red blood cells on postoperative complications after free muscle sparing transverse rectus abdominis myocutaneous flap surgery for breast reconstruction. Microsurgery. 2014;34(6):434-438.

136. Lymperopoulos NS, Sofos S, Constantinides J, Koshy O, Graham $\mathrm{K}$. Blood loss and transfusion rates in DIEP flap breast reconstruction. Introducing a new predictor. J Plast Reconstr Aesthet Surg. 2013;66(12):1659-1664.

137. Macdonald CR, Reeve W, Hazari A. The use of blood products in free flap based breast reconstruction: a cost and safety analysis. J Plast Reconstr Aesthet Surg. 2014;67(5):732-733.

138. O’Neill AC, Barandun M, Cha J, Zhong T, Hofer SO. Restrictive use of perioperative blood transfusion does not increase complication rates in microvascular breast reconstruction. J Plast Reconstr Aesthet Surg. 2016;69(8):1092-1096.

139. Kroll SS, Sharma S, Koutz C, et al. Postoperative morphine requirements of free TRAM and DIEP flaps. Plast Reconstr Surg. 2001;107(2):338-341.

140. Vega SJ, Bossert RP, Serletti JM. Improving outcomes in bilateral breast reconstruction using autogenous tissue. Ann Plast Surg. 2006;56(5):487-490; discussion 490-481.

141. Zoghbi Y, Gerth DJ, Tashiro J, Golpanian S, Thaller SR. Deep inferior epigastric perforator versus free transverse rectus abdominis myocutaneous flap: complications and resource utilization. Ann Plast Surg. 2017;78(5):516-520.

142. Chevray PM. Breast reconstruction with superficial inferior epigastric artery flaps: a prospective comparison with TRAM and DIEP flaps. Plast Reconstr Surg. 2004;114(5):1077-1083; discussion 1084-1075.

143. Atisha D, Alderman AK. A systematic review of abdominal wall function following abdominal flaps for postmastectomy breast reconstruction. Ann Plast Surg. 2009;63(2):222-230.
144. Egeberg A, Rasmussen MK, Sorensen JA. Comparing the donor-site morbidity using DIEP, SIEA or MS-TRAM flaps for breast reconstructive surgery: a meta-analysis. J Plast Reconstr Aesthet Surg. 2012;65(11):1474-1480.

145. Man LX, Selber JC, Serletti JM. Abdominal wall following free TRAM or DIEP flap reconstruction: a meta-analysis and critical review. Plast Reconstr Surg. 2009;124(3):752-764.

146. Wang XL, Liu LB, Song FM, Wang QY. Meta-analysis of the safety and factors contributing to complications of MS-TRAM, DIEP, and SIEA flaps for breast reconstruction. Aesthetic Plast Surg. 2014;38(4):681-691.

147. Macadam SA, Zhong T, Weichman K, et al. Quality of life and patientreported outcomes in breast cancer survivors: a multicenter comparison of four abdominally based autologous reconstruction methods. Plast Reconstr Surg. 2016;137(3):758-771.

148. Mosahebi A, Da Lio A, Mehrara BJ. The use of a pectoralis major flap to improve internal mammary vessels exposure and reduce contour deformity in microvascular free flap breast reconstruction. Ann Plast Surg. 2008;61(1):30-34.

149. Darcy CM, Smit JM, Audolfsson T, Acosta R. Surgical technique: the intercostal space approach to the internal mammary vessels in 463 microvascular breast reconstructions. J Plast Reconstr Aesthet Surg. 2011;64(1):58-62.

150. Kim H, Lim SY, Pyon JK, et al. Rib-sparing and internal mammary artery-preserving microsurgical breast reconstruction with the free DIEP flap. Plast Reconstr Surg. 2013;131(3):327e-334e.

151. Mickute Z, Di Candia M, Moses M, Bailey AR, Malata CM. Analgesia requirements in patients undergoing DIEP flap breast reconstructions: rib preservation versus rib sacrifice. J Plast Reconstr Aesthet Surg. 2010;63(12):e837-e839.

152. Parrett BM, Caterson SA, Tobias AM, Lee BT. The rib-sparing technique for internal mammary vessel exposure in microsurgical breast reconstruction. Ann Plast Surg. 2008;60(3):241-243.

153. Sacks JM, Chang DW. Rib-sparing internal mammary vessel harvest for microvascular breast reconstruction in 100 consecutive cases. Plast Reconstr Surg. 2009;123(5):1403-1407.

154. Wilson S, Weichman K, Broer PN, et al. To resect or not to resect: the effects of rib-sparing harvest of the internal mammary vessels in microsurgical breast reconstruction. J Reconstr Microsurg. 2016;32(2): 94-100.

155. Zeng A, Zhu L, Liu Z, et al. [Rib-sparing technique for internal mammary vessels exposure and anastomosis in breast reconstruction with deep inferior epigastric perforator flap]. Zhongguo Xiu Fu Chong Jian Wai Ke Za Zhi. 2014;28(11):1376-1379.

156. Eberhart LH, Morin AM, Wulf H, Geldner G. Patient preferences for immediate postoperative recovery. Br J Anaesth. 2002;89(5): 760-761

157. Lee A, Gin T, Lau AS, Ng FF. A comparison of patients' and health care professionals' preferences for symptoms during immediate postoperative recovery and the management of postoperative nausea and vomiting. Anesth Analg. 2005;100(1):87-93.

158. Macario A, Weinger M, Carney S, Kim A. Which clinical anesthesia outcomes are important to avoid? The perspective of patients. Anesth Analg. 1999;89(3):652-658.

159. Apfelbaum JL, Silverstein JH, Chung FF, et al; American Society of Anesthesiologists Task Force on Postanesthetic Care. Practice guidelines for postanesthetic care: an updated report by the American Society of Anesthesiologists task force on postanesthetic care. Anesthesiology. 2013;118(2):291-307.

160. De Oliveira GS Jr, Castro-Alves LJ, Ahmad S, Kendall MC, McCarthy RJ. Dexamethasone to prevent postoperative nausea and vomiting: an updated meta-analysis of randomized controlled trials. Anesth Analg. 2013;116(1):58-74.

161. Apfel CC, Zhang K, George E, et al. Transdermal scopolamine for the prevention of postoperative nausea and vomiting: a systematic review and meta-analysis. Clin Ther. 2010;32(12):1987-2002. 
162. Gan TJ, Sinha AC, Kovac AL, et al; TDS Study Group. A randomized, double-blind, multicenter trial comparing transdermal scopolamine plus ondansetron to ondansetron alone for the prevention of postoperative nausea and vomiting in the outpatient setting. Anesth Analg. 2009;108(5):1498-1504.

163. Sah N, Ramesh V, Kaul B, Dalby P, Shestak K, Vallejo MC. Transdermal scopolamine patch in addition to ondansetron for postoperative nausea and vomiting prophylaxis in patients undergoing ambulatory cosmetic surgery. J Clin Anesth. 2009;21(4):249-252.

164. Jones S, Strobl R, Crosby D, Burkard JF, Maye J, Pellegrini JE. The effect of transdermal scopolamine on the incidence and severity of postoperative nausea and vomiting in a group of high-risk patients given prophylactic intravenous ondansetron. AANA J. 2006;74(2): 127-132.

165. Awad IT, Murphy D, Stack D, Swanton BJ, Meeke RI, Shorten GD. A comparison of the effects of droperidol and the combination of droperidol and ondansetron on postoperative nausea and vomiting for patients undergoing laparoscopic cholecystectomy. J Clin Anesth. 2002;14(7): $481-485$.

166. Carlisle JB, Stevenson CA. Drugs for preventing postoperative nausea and vomiting. Cochrane Database Syst Rev. 2006;3:CD004125.

167. Derry C, Derry S, Moore RA, McQuay HJ. Single dose oral ibuprofen for acute postoperative pain in adults. Cochrane Database Syst Rev. 2009;3:CD001548.

168. Elia N, Lysakowski C, Tramer MR. Does multimodal analgesia with acetaminophen, nonsteroidal antiinflammatory drugs, or selective cyclooxygenase- 2 inhibitors and patient-controlled analgesia morphine offer advantages over morphine alone? Meta-analyses of randomized trials. Anesthesiology. 2005;103(6):1296-1304.

169. Marret E, Kurdi O, Zufferey P, Bonnet F. Effects of nonsteroidal antiinflammatory drugs on patient-controlled analgesia morphine side effects: meta-analysis of randomized controlled trials. Anesthesiology. 2005;102(6):1249-1260.

170. Kelley BP, Bennett KG, Chung KC, Kozlow JH. Ibuprofen may not increase bleeding risk in plastic surgery: a systematic review and meta-analysis. Plast Reconstr Surg. 2016;137(4):1309-1316.

171. De Oliveira GS Jr, Agarwal D, Benzon HT. Perioperative single dose ketorolac to prevent postoperative pain: a meta-analysis of randomized trials. Anesth Analg. 2012;114(2):424-433.

172. Sharma S, Chang DW, Koutz C, et al. Incidence of hematoma associated with ketorolac after TRAM flap breast reconstruction. Plast Reconstr Surg. 2001;107(2):352-355.

173. Stephens DM, Richards BG, Schleicher WF, Zins JE, Langstein HN. Is ketorolac safe to use in plastic surgery? A critical review. Aesthet Surg J. 2015;35(4):462-466.

174. Toms L, McQuay HJ, Derry S, Moore RA. Single dose oral paracetamol (acetaminophen) for postoperative pain in adults. Cochrane Database Syst Rev. 2008;4:CD004602.
175. Ong CK, Seymour RA, Lirk P, Merry AF. Combining paracetamol (acetaminophen) with nonsteroidal antiinflammatory drugs: a qualitative systematic review of analgesic efficacy for acute postoperative pain. Anesth Analg. 2010;110(4):1170-1179.

176. Doleman B, Heinink TP, Read DJ, Faleiro RJ, Lund JN, Williams JP. A systematic review and meta-regression analysis of prophylactic gabapentin for postoperative pain. Anaesthesia. 2015;70(10): 1186-1204.

177. Clarke H, Bonin RP, Orser BA, Englesakis M, Wijeysundera DN, Katz $\mathrm{J}$. The prevention of chronic postsurgical pain using gabapentin and pregabalin: a combined systematic review and meta-analysis. Anesth Analg. 2012;115(2):428-442.

178. Ho KY, Gan TJ, Habib AS. Gabapentin and postoperative pain - a systematic review of randomized controlled trials. Pain. 2006;126(1-3):91-101.

179. Mathiesen O, Moiniche S, Dahl JB. Gabapentin and postoperative pain: a qualitative and quantitative systematic review, with focus on procedure. BMC Anesthesiol. 2007;7:6.

180. Castelino T, Fiore JF Jr, Niculiseanu P, Landry T, Augustin B, Feldman LS. The effect of early mobilization protocols on postoperative outcomes following abdominal and thoracic surgery: a systematic review. Surgery. 2016;159(4):991-1003.

181. Epstein NE. A review article on the benefits of early mobilization following spinal surgery and other medical/surgical procedures. Surg Neurol Int. 2014;5(suppl 3):S66-S73.

182. Yeung JK, Harrop R, McCreary O, et al. Delayed mobilization after microsurgical reconstruction: an independent risk factor for pneumonia. Laryngoscope. 2013;123(12):2996-3000.

183. Griffiths R, Fernandez R. Strategies for the removal of short-term indwelling urethral catheters in adults. Cochrane Database Syst Rev. 2007;2:CD004011.

184. Ramanathan R, Duane TM. Urinary tract infections in surgical patients. Surg Clin North Am. 2014;94(6):1351-1368.

185. Zhang P, Hu WL, Cheng B, Cheng L, Xiong XK, Zeng YJ. A systematic review and meta-analysis comparing immediate and delayed catheter removal following uncomplicated hysterectomy. Int Urogynecol J. 2015;26(5):665-674.

186. Charoenkwan K, Matovinovic E. Early versus delayed oral fluids and food for reducing complications after major abdominal gynaecologic surgery. Cochrane Database Syst Rev. 2014;12:CD004508.

187. Willcutts KF, Chung MC, Erenberg CL, Finn KL, Schirmer BD, Byham-Gray LD. Early oral feeding as compared with traditional timing of oral feeding after upper gastrointestinal surgery: a systematic review and meta-analysis. Ann Surg. 2016;264(1):54-63.

188. Lee VS, Kawamoto K, Hess R, et al. Implementation of a value-driven outcomes program to identify high variability in clinical costs and outcomes and association with reduced cost and improved quality. JAMA. 2016;316(10):1061-1072.

\section{Journal of Pain Research}

\section{Publish your work in this journal}

The Journal of Pain Research is an international, peer reviewed, open access, online journal that welcomes laboratory and clinical findings in the fields of pain research and the prevention and management of pain. Original research, reviews, symposium reports, hypothesis formation and commentaries are all considered for publication.

\section{Dovepress}

The manuscript management system is completely online and includes a very quick and fair peer-review system, which is all easy to use. Visit http://www.dovepress.com/testimonials.php to read real quotes from published authors. 